\title{
Computing the Nonabelian Tensor Square of Metacyclic $p$-Groups of Nilpotency Class Two
}

\author{
A. M. Basri ${ }^{a}$, N. H. Sarmin ${ }^{a^{*}}$, N. M. Mohd Ali ${ }^{a}$, J. R. Beuerle ${ }^{b}$ \\ ${ }^{a}$ Department of Mathematical Sciences, Faculty of Science, Universiti Teknologi Malaysia,81310 UTM Johor Bahru, Johor, Malaysia \\ ${ }^{b}$ Mathematics and Statistics Department, Elon University, North Carolina, USA \\ *Corresponding author: nhs@utm.my
}

\section{Article history}

Received :15 October 2012

Received in revised form :30

December 2012

Accepted :12 February 2013

\begin{abstract}
In this paper, we develop appropriate programme using Groups, Algorithms and Programming (GAP) software enables performing different computations on various characteristics of all finite nonabelian metacyclic $p$-groups, $p$ is prime, of nilpotency class 2 . Such programme enables to compute structure of the group, order of the group, structure of the center, the number of conjugacy classes, structure of commutator subgroup, abelianization, Whitehead`s universal quadratic functor and other characteristics. In addition, structures of some other groups such as the nonabelian tensor square and various homological functors including Schur multiplier and exterior square can be computed using this programme. Furthermore, by computing the epicenter order or the exterior center order the capability can be determined. In our current article, we only compute the nonabelian tensor square of certain order groups, as an example, and give GAP codes for computing other characteristics and some subgroups.
\end{abstract}

Keywords: -Groups; Metacyclic groups; groups; algorithms and programming

\begin{abstract}
Abstrak
Dalam kertas kerja ini, kami menyediakan satu program yang sesuai menggunakan perisian Groups, Algorithms dan Programming (GAP) yang berupaya mempersembahkan pengiraan yang berbeza terhadap pelbagai cirian kepada semua kumpulan-p metakitaran nilpoten kelas dua terhingga, p ialah perdana. Program ini mampu mengira struktur kumpulan, peringkat kumpulan, struktur pusat, nombor kelas kekonjugatan, struktur subkumpulan penukar tertib, keabelanan, fungtor kuadratik Whitehead's semesta dan cirian-cirian lain. Tambahan pula, struktur kepada kumpulan-kumpulan yang lain seperti kuasa dua tensor tak abelan dan pelbagai fungtor homologi termasuk pendarab Schur dan kuasa dua peluaran, boleh dikira menggunakan program ini. Selain itu, melalui pengiraan peringkat epipusat atau peringkat pusat peluaran, keberupayaan boleh ditentukan. Dalam artikel terkini, kami hanya mengira kuasa dua tensor tak abelan kepada peringkat kumpulan tertentu, sebagai contoh, kod GAP yang diberi untuk mengira ciriancirian lain dan sesetengah subkumpulan.
\end{abstract}

Kata kunci: Kumpulan-p; kumpulan metakitaran; Groups; Algorithms and Programming

(c) 2012 Penerbit UTM Press. All rights reserved.

\subsection{INTRODUCTION}

A group $G$ is metacyclic if it contains a cyclic normal subgroup $N$ such that $G / N$ is also cyclic. Finite metacyclic groups can be presented on two generators and three defining relations. Some specific types of metacyclic groups have been given much attention. Zassenhaus discussed metacyclic groups with cyclic commutator quotient, as did Hall. Beyl, King, Liedahl, Newman and Xu, Rédei and Lindenberg all classified metacyclic $p$-groups of odd order. Significant progress was made in 1994 when Sim proved in [1] that every finite metacyclic group can be decomposed naturally as a semidirect product of two Hall subgroups [2].
A $p$-group is a group in which each element has a power of $p$ as its order whereas a finite group is a $p$-group if and only if its order is a power of $p$ [3].

By Beuerle [4], a metacyclic $p$-group is usually given by a presentation of the form:

$$
G=\left\langle a, b ; a^{p^{m}}=1, b^{p^{n}}=a^{k}, b a b^{-1}=a^{r}\right\rangle,
$$

where $m, n \geq 0, \quad r>0, \quad k \leq p^{m}, \quad p^{m} \mid k(r-1) \quad$ and $p^{m} \mid r^{p^{n}}-1$.

Metacyclic $p$-groups are divided by Beuerle [4] into two main classes as follows: 
$G_{p}(\alpha, \beta, \varepsilon, \delta, \pm)=$

$\left\langle a, b ; a^{p^{\alpha}}=1, b^{p^{\beta}}=a^{p^{\alpha-\varepsilon}}, b a b^{-1}=a^{r}\right\rangle$

where $r=p^{\alpha-\delta}+1$ or $r=p^{\alpha-\delta}-1$. We say that the group is of positive or negative type if $r=p^{\alpha-\delta}+1$ or $r=p^{\alpha-\delta}-1$, respectively.

For short, we write $G_{+}$and $G_{-}$for $G_{p}(\alpha, \beta, \varepsilon, \delta,+)$ and $G_{p}(\alpha, \beta, \varepsilon, \delta,-)$ respectively.

The following proposition gives a standardized parametric presentation of metacyclic $p$-groups.

Proposition 1: [4] Let $G$ be a finite metacyclic $p$-group. Then there exist integers $\alpha, \beta, \delta, \varepsilon$ with $\alpha, \beta>0$ and $\delta$, $\varepsilon$ nonnegative, where $\delta \leq \min \{\alpha-1, \beta\}$ and $\delta+\varepsilon \leq \alpha$ such that for an odd prime $p, G \cong G_{p}(\alpha, \beta, \varepsilon, \delta,+)$. If $p=2$, then in addition $\alpha-\delta>1$ and $G \cong G_{2}(\alpha, \beta, \varepsilon, \delta$, + ) or $G \cong G_{p}(\alpha, \beta, \varepsilon, \delta,-)$, where in the second case $\varepsilon \leq 1$. Moreover, if $G$ is of positive type, then $\delta>0$ for all $p$. Some of the basic properties and various subgroups are given in the next proposition:

Proposition 2: [4] Let $G$ be a group of type $G_{p}(\alpha, \beta, \varepsilon, \delta, \pm)$ and $k \geq 1$. Then we have the following results for the order of $G$, the center of $G$, the order of the center of $G$, the derived subgroups of $G$, the order of the derived subgroups of $G$ and the exponent of $G$ :

\begin{tabular}{|c|c|c|}
\cline { 2 - 3 } \multicolumn{1}{c|}{} & $G_{+}$ & $G_{-}$ \\
\hline$\left|G_{ \pm}\right|$ & \multicolumn{2}{c|}{$p^{\alpha+\beta}$} \\
\hline $\mathrm{Z}\left(G_{ \pm}\right)$ & $\left\langle a^{p^{\delta}}, b^{p^{\delta}}\right\rangle$ & $\left\langle a^{2^{\alpha-1}}, b^{2^{\max \{1, \delta\}}}\right\rangle$ \\
\hline$\left|\mathrm{Z}\left(G_{ \pm}\right)\right|$ & $p^{\alpha+\beta-2 \delta}$ & $2^{1+\beta-\max \{1, \delta\}}$ \\
\hline$\gamma_{k+1}\left(G_{ \pm}\right)$ & $\left\langle a^{p^{k(\alpha-\delta)}}\right\rangle$ & $\left\langle a^{2^{k}}\right\rangle$ \\
\hline$\left|\gamma_{k+1}\left(G_{ \pm}\right)\right|$ & $p^{\max \{0, k \delta-(k-1) \alpha\}}$ & $2^{\max \{0, \alpha-k\}}$ \\
\hline $\operatorname{Exp}\left(G_{ \pm}\right)$ & \multicolumn{2}{|c|}{$p^{\max \{\alpha, \beta+\varepsilon\}}$} \\
\hline
\end{tabular}

Moreover, if $\beta>\max \{1, \delta\}$ then $Z\left(G_{-}\right)$is cyclic if and only if $\varepsilon=1$.

In [4], Beuerle classified all finite nonabelian metacyclic $p$ groups. Using this classification, we develop appropriate programme using Groups, Algorithms and Programming (GAP) software enables performing different computations on various characteristics of all finite nonabelian metacyclic $p$-groups, $p$ is prime, of nilpotency class 2 . Such programme enables to compute structure of the group, order of the group, structure of the center, the number of conjugacy classes, commutator subgroup, abelianization, Whitehead`s universal quadratic functor and other characteristics. In addition, structures of some other groups such as the nonabelian tensor square and various homological functors including Schur multiplier and exterior square can be computed using this programme. Furthermore, by computing the epicenter order or the exterior center order the capability can be determined. In our current article, we only compute the nonabelian tensor square of certain order groups, as an example, and GAP codes for computing other characteristics and some subgroups given.

The nonabelian tensor square is defined as follows:

Definition 1: [5] For a group $G$, the nonabelian tensor square, $G \otimes G$, is generated by the symbols $g \otimes h$, where $g, h \in G$, subject to the relations;

$$
\begin{aligned}
& g g^{\circ} \otimes h=\left({ }^{g} g^{\cdot} \otimes{ }^{g} h\right)(g \otimes h) \text { and } \\
& g \otimes h h^{\prime}=(g \otimes h)\left({ }^{h} g \otimes{ }^{h} h^{\prime}\right)
\end{aligned}
$$

for all $g, g, h, h \in G$, where ${ }^{h} g=h g h^{-1}$ denotes the conjugate of $g$ by $h$.

GAP is a system for computational discrete algebra, with emphasis on computational group theory. GAP provides a programming language, a library of functions that implement algebraic algorithms written in the GAP language as well as libraries of algebraic objects such as for all non-isomorphic groups up to order 2000. GAP can be a useful pedagogical tool in different ways such as a fancy calculator, a way to provide large or complicated examples, a way for researcher to write simple computer algorithms, a way for producing large amounts of data so that the researcher can formulate a conjecture and a mean for researchers to work in collaboration [6].

\subsection{PRELIMINARIES AND SOME BASIC DIEFINITIONS}

In this section, some preliminaries and basic definitions will be needed throughout the paper is presented.

Definition 2: [4] Let $p$ be a prime and $n$ a non-negative integer. If $n \neq 0$, then denote by $[n]_{p}$ the largest integer such that $p^{[n]_{p}}$ divides $n$. Set $[0]_{p}=0$.

Definition 3: [3] Let $G$ be a group and $a \in G$. If there is a positive integer $n$ such that $a^{n}=e$, then the least positive integer $n$ is the order of $a$. If no such $n$ exists, then $a$. is of infinite order.

Definition 4: [3] A p-group is a group in which each element has a power of $p$ as its order. A finite group is a $p$-group if and only if its order is a power of $p$.

Definition 5: [3] The centre $Z(G)$ of a group $G$ is the set of elements in $G$ that commute with every element of $G$. In symbols, $Z(G)=\{a \in G: a x=x a$ for all $x$ in $G\}$.

Definition 6: [7] A group $G$ is called nilpotent if it has a central series. The length of the shortest central series is the nilpotent class of $G$. 


\subsection{THE CLASSIFICATION OF GROUPS}

In this section, the classification of all finite nonabelian metacyclic $p$-groups of nilpotency class 2 done by Beuerle in [4] is stated.

$$
\begin{aligned}
& G \cong\left\langle a, b ; a^{p^{\alpha}}=b^{p^{\beta}}=1,[a, b]=a^{p^{\alpha-\delta}}\right\rangle, \\
& \text { where } \alpha, \beta, \delta \in \mathbb{N}, \alpha \geq 2 \delta, \beta \geq \delta \geq 1 ; \\
& G=Q \cong\left\langle a, b ; a^{4}=1, b^{2}=[a, b]=a^{2}\right\rangle, \\
& \text { the group of Quaternion of order } 8 .
\end{aligned}
$$

\subsection{GAP PROGRAMMES}

In this section, we use GAP to develop appropriate coding for computing different characteristics of the groups and the structure of various subgroups for some small order groups of types (2.1) and (2.2). We provide GAP programmes generating general codes to create the finite presentation of the groups and compute the nonabelian tensor square of some small order groups of types (2.1) and (2.2), as examples.

\subsection{Type (2.1)}

First, we use GAP programme to generate all finite nonabelian metacyclic $p$-groups of type (2.1) and construct some examples.

\subsubsection{Generating Type (2.1)}

In this section we develop the GAP coding to generate all finite nonabelian metacyclic $p$-groups of type (2.1).

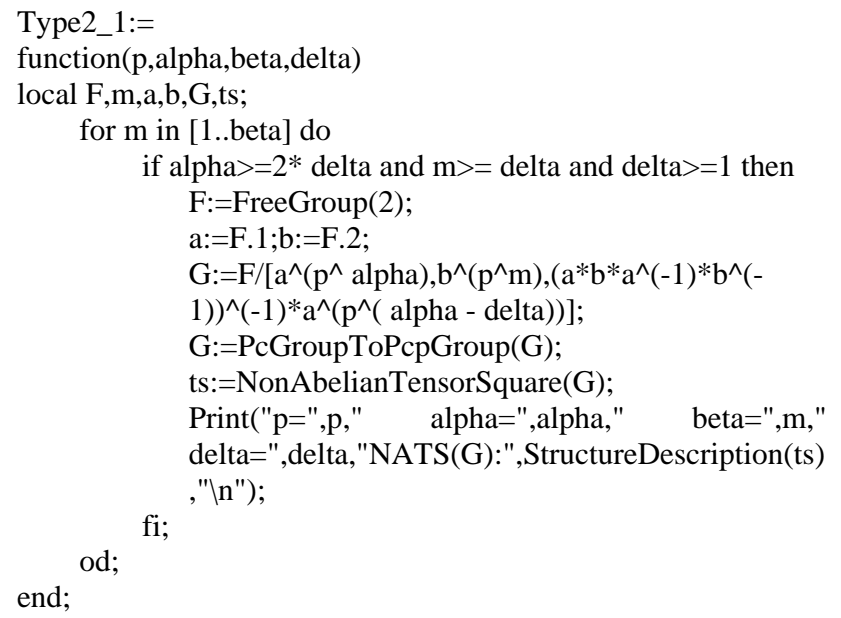

We defined the group with four parameters which are $p, \alpha, \beta$ and $\delta$. The GAP code below is used to create the finite presentation of the group.

F:=FreeGroup(2);

$\mathrm{a}:=\mathrm{F} .1 ; \mathrm{b}:=\mathrm{F} .2$;

$\mathrm{G}:=\mathrm{F} /\left[\mathrm{a}^{\wedge}\left(\mathrm{p}^{\wedge} \quad\right.\right.$ alpha $), \mathrm{b}^{\wedge}\left(\mathrm{p}^{\wedge} \mathrm{m}\right),\left(\mathrm{a}^{*} \mathrm{~b}^{*} \mathrm{a}^{\wedge}(-1)^{*} \mathrm{~b}^{\wedge}(-1)\right)^{\wedge}(-1)^{*} \mathrm{a}^{\wedge}\left(\mathrm{p}^{\wedge}(\right.$ alpha - delta))];

\subsubsection{Constructing Examples of Type (2.1)}

Now, we define the parameters and put them in GAP. For example, we define $p=2, \alpha=2, \beta=1$ to 6 and $\delta=1$. First we need to read the file and call the function (here $\beta=1,2,3,4,5,6$ ).

gap> Type2_1(2,2,6,1);

$\mathrm{p}=2$ alpha=2 beta=1 delta=1 NATS(G): $\mathrm{C}_{4} \times \mathrm{C}_{2} \times \mathrm{C}_{2} \times \mathrm{C}_{2}$

$\mathrm{p}=2$ alpha=2 beta=2 delta=1 NATS(G): $\mathrm{C}_{4} \times \mathrm{C}_{4} \times \mathrm{C}_{4} \times \mathrm{C}_{2}$

$\mathrm{p}=2$ alpha=2 beta=3 delta=1 NATS(G): $\mathrm{C}_{8} \times \mathrm{C}_{4} \times \mathrm{C}_{4} \times \mathrm{C}_{2}$

$\mathrm{p}=2$ alpha=2 beta=4 delta=1 NATS(G): $\mathrm{C}_{16} \times \mathrm{C}_{4} \times \mathrm{C}_{4} \times \mathrm{C}_{2}$

$\mathrm{p}=2$ alpha=2 beta=5 delta=1 NATS(G): $\mathrm{C}_{32} \times \mathrm{C}_{4} \times \mathrm{C}_{4} \times \mathrm{C}_{2}$

$\mathrm{p}=2$ alpha $=2$ beta=6 delta $=1 \mathrm{NATS}(\mathrm{G}): \mathrm{C}_{64} \times \mathrm{C}_{4} \times \mathrm{C}_{4} \times \mathrm{C}_{2}$

For $p=3$, we define the parameters and put them in GAP. For example, we define $\alpha=2, \beta=1$ to 6 and $\delta=1$. Thus, we get the following results:

gap> Type2_1(3,2,6,1);

$\mathrm{p}=3$ alpha $=2$ beta=1 delta=1 NATS(G): $\mathrm{C}_{3} \times \mathrm{C}_{3} \times \mathrm{C}_{3} \times \mathrm{C}_{3}$ $\mathrm{p}=3$ alpha=2 beta=2 delta=1 NATS(G): $\mathrm{C}_{9} \times \mathrm{C}_{9} \times \mathrm{C}_{3} \times \mathrm{C}_{3}$ $\mathrm{p}=3$ alpha=2 beta=3 delta=1 NATS(G): $\mathrm{C}_{27} \times \mathrm{C}_{9} \times \mathrm{C}_{3} \times \mathrm{C}_{3}$ $\mathrm{p}=3$ alpha $=2$ beta=4 delta=1 NATS(G): $\mathrm{C}_{81} \times \mathrm{C}_{9} \times \mathrm{C}_{3} \times \mathrm{C}_{3}$ $\mathrm{p}=3$ alpha=2 beta=5 delta=1 NATS(G): $\mathrm{C}_{243} \times \mathrm{C}_{9} \times \mathrm{C}_{3} \times \mathrm{C}_{3}$ $\mathrm{p}=3$ alpha $=2$ beta=6 delta=1 NATS(G): $\mathrm{C}_{729} \times \mathrm{C}_{9} \times \mathrm{C}_{3} \times \mathrm{C}_{3}$ With similar to the above, we can get much more results for different primes, $p$, and different values of the parameters $\alpha, \beta$ and $\delta$.

\subsubsection{Summary of GAP Results}

A summary of GAP results for type (2.1), as shown in section 4.1.2, is given in the following table:

Table 1 GAP results for type (2.1)

\begin{tabular}{cccccc}
\hline$\#$ & $p$ & $\alpha$ & $\beta$ & $\delta$ & $G \otimes G$ \\
\hline 1 & 2 & 2 & 1 & 1 & $\mathrm{C}_{4} \times \mathrm{C}_{2} \times \mathrm{C}_{2} \times \mathrm{C}_{2}$ \\
2 & 2 & 2 & 2 & 1 & $\mathrm{C}_{4} \times \mathrm{C}_{4} \times \mathrm{C}_{4} \times \mathrm{C}_{2}$ \\
3 & 2 & 2 & 3 & 1 & $\mathrm{C}_{8} \times \mathrm{C}_{4} \times \mathrm{C}_{4} \times \mathrm{C}_{2}$ \\
4 & 2 & 2 & 4 & 1 & $\mathrm{C}_{16} \times \mathrm{C}_{4} \times \mathrm{C}_{4} \times \mathrm{C}_{2}$ \\
5 & 2 & 2 & 5 & 1 & $\mathrm{C}_{32} \times \mathrm{C}_{4} \times \mathrm{C}_{4} \times \mathrm{C}_{2}$ \\
6 & 2 & 2 & 6 & 1 & $\mathrm{C}_{64} \times \mathrm{C}_{4} \times \mathrm{C}_{4} \times \mathrm{C}_{2}$ \\
7 & 3 & 2 & 1 & 1 & $\mathrm{C}_{3} \times \mathrm{C}_{3} \times \mathrm{C}_{3} \times \mathrm{C}_{3}$ \\
8 & 3 & 2 & 2 & 1 & $\mathrm{C}_{9} \times \mathrm{C}_{9} \times \mathrm{C}_{3} \times \mathrm{C}_{3}$ \\
9 & 3 & 2 & 3 & 1 & $\mathrm{C}_{27} \times \mathrm{C}_{9} \times \mathrm{C}_{3} \times \mathrm{C}_{3}$ \\
10 & 3 & 2 & 4 & 1 & $\mathrm{C}_{81} \times \mathrm{C}_{9} \times \mathrm{C}_{3} \times \mathrm{C}_{3}$ \\
11 & 3 & 2 & 5 & 1 & $\mathrm{C}_{243} \times \mathrm{C}_{9} \times \mathrm{C}_{3} \times \mathrm{C}_{3}$ \\
12 & 3 & 2 & 6 & 1 & $\mathrm{C}_{729} \times \mathrm{C}_{9} \times \mathrm{C}_{3} \times \mathrm{C}_{3}$ \\
\hline
\end{tabular}




\subsection{Type (2.2)}

With similar objective as for groups of type (2.1), we produce GAP algorithms for groups of type (2.2).

gap> F:=FreeGroup(2);

$<$ free group on the generators [ f1, f2 ]>

gap> a:=F.1;b:=F.2;

f1

$\mathrm{f} 2$

gap $>\quad Q:=F /\left[a \wedge 4, b^{\wedge} 2^{*}\left(a^{*} b^{*} a^{\wedge}(-1)^{*} b^{\wedge}(-1)\right)^{\wedge}(-1), \quad b^{*} a^{\wedge}(-1)^{*} b^{\wedge}(-\right.$ $\left.1) * \mathrm{a}^{\wedge}(-1), \mathrm{b}^{\wedge} 2 * \mathrm{a}^{\wedge}(-2)\right]$;

$<$ fp group on the generators [ $\mathrm{f} 1, \mathrm{f} 2]>$

gap> StructureDescription(NonAbelianTensorSquare(Q));

$\mathrm{C}_{4} \times \mathrm{C}_{4} \times \mathrm{C}_{2} \times \mathrm{C}_{2}$

gap> LogTo();

\subsubsection{Remark 1}

Table 1 and the finding for the structure of the nonabelian tensor square computed in section 4.2 shows that our numerical results produced by GAP have verified the following proposition given in [8] and [9]:

Proposition 3: Let $G$ be a metacyclic $p$-group of class 2. If $G$ is of type (2.1), then

$$
G \otimes G \cong C_{p^{\alpha-\delta+[p]} 2} \times C_{p^{\min \{\alpha, \beta\}}} \times C_{p^{\min \{\alpha-\delta, \beta\}}} \times C_{2^{\beta}} .
$$

If $G$ is of type (2.2), then

$$
G \otimes G \cong C_{4} \times C_{4} \times C_{2} \times C_{2} .
$$

\subsubsection{Remark 2}

Below are GAP codes for computing certain characteristics and subgroups.

\begin{tabular}{|c|c|}
\cline { 2 - 2 } \multicolumn{1}{c|}{} & GAP Codes \\
\hline Order of group & Order(G) \\
\hline Center of group & Centre(G) \\
\hline Nilpotency class & NilpotencyClassOfGroup(G) \\
\hline Commutator subgroup & DhivedSubgroup(G) \\
\hline $\begin{array}{c}\text { Whitehead`s universal } \\
\text { quadratic functor }\end{array}$ & NonAbelianTensorSquare(G) \\
\hline $\begin{array}{c}\text { Nonabelian tensor square } \\
\text { Schur multiplier }\end{array}$ & SchurMultiplicator(G) \\
\hline Exterior square & NonAbelianExteriorSquare(G) \\
\hline Epicenter & Epicenter(G) \\
\hline Exterior center & ExteriorCenter(G) \\
\hline
\end{tabular}

\subsection{CONCLUSION}

In this paper we have constructed appropriate programme using Groups, Algorithms and Programming (GAP) software to compute different characteristics such as structure of the group, order of the group, structure of the center, the number of conjugacy classes, commutator subgroup, abelianization, Whitehead's universal quadratic functor and other characteristics of all finite nonabelian metacyclic $p$-groups, $p$ is prime, of nilpotency class 2 . In addition, such programme enables perform computation on structures of some other groups such as the nonabelian tensor square and various homological functors including Schur multiplier and exterior square. Furthermore, by computing the epicenter order or the exterior Center order the capability can be determined.

To illustrate Proposition 3, the nonabelian tensor square of certain order groups computed, as an example. We found that the nonabelian tensor square of all computed groups of type (2.1) is a direct product of four cyclic groups and the nonabelian tensor square of type (2.2), Quaternion group of order 8, is $\mathrm{C}_{4} \times$ $\mathrm{C}_{4} \times \mathrm{C}_{2} \times \mathrm{C}_{2}$. It is worth to mention that our findings verify the theoretic findings in Proposition 3.

Finally, GAP codes for computing certain characteristics and subgroups given.

\section{Acknowledgement}

The authors would like to acknowledge Universiti Teknologi Malaysia for the partial funding of this research through the Research University Grant (RUG) vote No 05J46

\section{References}

[1] H-S Sim. 1994. Metacyclic Groups of Odd Order, Proc. London Math. Soc. 3(69): 47-71.

[2] C. E. Hempel. 2000. Metacyclic Groups, Bull. Austral. Math. Soc. 61: 523-524.

[3] J. B. Fraleigh. 1982. First Course In Abstract Algebra. Addison Wesley, USA.

[4] J. Beuerle. 2005. An Elementary Classification of Finite Metacyclic $p$ Groups of Class at Least Three. Algebra Colloquium. Soc. 43. 553562.

[5] R. Brown, D. L. Johnson and E. F. Robertson. 1987. Some Computations of Nonabelian Tensor Products of Groups. J. Algebra. 111. 177-202.

[6] J. G. Rainbolt, J. A. Gallian. 2010. Abstract Algebra With GAP. Books/Cole, Cengage Learning, Boston.

[7] D. J. S. Robinson. 1993. A Course in the Theory of Groups. SpringerVerlag, Berlin.

[8] M. Bacon, L-C Kappe. 1993. The Nonabelian Tensor Square of A 2generator $p$-groups of Class 2. Arch. Math. 61: 508-516.

[9] L-C Kappe, N. Sarmin and M. Visscher.1999. Two-Generator 2groups of Class 2 and Their Nonabelian Tensor Squares. Glasgow Math. J. 41: 417-430. 